\author{
Álvaro José Montoya \\ Universidade Federal de Viçosa \\ Maria das Dores Saraiva de Loreto \\ Universidade Federal de Viçosa \\ Karla Maria Damiano Teixeira \\ Universidade Federal de Viçosa
}

\title{
O perfil socioeconômico das donas de casa na Nicarágua
}

\begin{abstract}
Resumo: O propósito deste artigo é caracterizar o perfil socioeconômico das donas de casa nicaraguenses e refletir sobre sua contribuição monetária para o Produto Interno Bruto. Os resultados da análise estatística mostraram que o trabalho doméstico, que em geral é invisível e não valorizado, é responsabilidade da mulher. Estimou-se que, em termos monetários, a massa salarial do trabalho doméstico em Nicarágua oscilaria entre $8,0 \%$ e $22,1 \%$ do PIB. Concluiu-se que, apesar de sua relevância na produção nacional, o lugar que a mulher ocupa na sociedade é determinado por seu papel na família, em função dos estereótipos de gênero. Palavras-chave: trabalho doméstico; gênero; contas nacionais; políticas públicas.
\end{abstract}

Copyright (c) 2015 by Revista Estudos Feministas.

1 CEPAL, 2010, p. 173-175.

${ }^{2}$ Neste artigo, considera-se trabaIho doméstico aquele sem fins lucrativos realizado por donas de casa, para fins de manutenção de sua residência e cuidado dos membros familiares.

\section{Introdução}

Apesar das intensas mudanças nas dinâmicas familiares e do aumento da participação das mulheres na força de trabalho, a atuação masculina nas tarefas domésticas ainda é considerada baixa na realidade Nicaraguense. As mulheres, por sua vez, suportam uma sobrecarga de trabalho, pois, mesmo estando inseridas no trabalho remunerado, mantêm o seu papel tradicional e naturalizado como cuidadoras da casa e dos filhos. ${ }^{1}$

A despeito da importância do trabalho doméstico, os indicadores tradicionais de medição da produção nacional não o consideram ${ }^{2}$ como parte da oferta total, o que representa não só uma forma de discriminação do trabalho familiar como também uma subestimação do produto nacional. Essa 


\begin{abstract}
é uma realidade não apenas da Nicarágua, mas de diferentes países do mundo, independentemente de seu grau de desenvolvimento econômico.

A literatura macroeconômica classifica a economia nicaraguense como "pequena e aberta", visto que, com um Produto Interno Bruto (PIB) de US\$1 1.256 milhões de dólares em 2013, contribuía somente com 7,1\% da produção total da América Central.

Considerando a revisão metodológica realizada no Sistema de Contas Nacionais em setembro de 2012, foram incluídas novas atividades que antes não eram contabilizadas formalmente na construção da oferta global. Assim, o PIB nicaraguense ficou $30 \%$ maior que aquele contabilizado pelo Sistema de Contas Nacionais anterior (ano-base 1994), como pode ser observado na Figura 1.
\end{abstract}

Figura 1 - PIB nominal da Nicarágua em 2011.

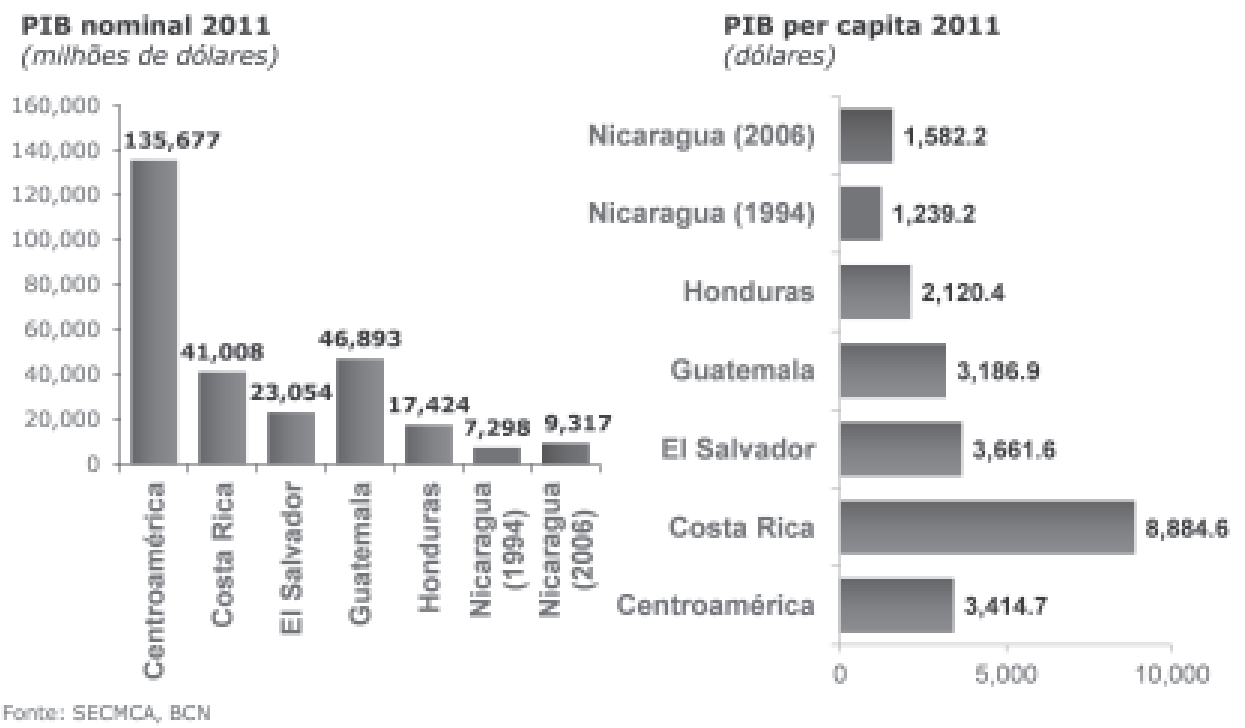

Fonte: SECMCA, BCN (2011, p. 12).

Segundo o Banco Central da Nicarágua ( $\mathrm{BCN})$, essa atualização metodológica deu como resultado tanto a ampliação do número de contas de produção (51 novas contas) quanto uma maior cobertura de algumas atividades. Os principais avanços decorreram da incorporação das atividades de telefonia móvel, call centers, serviços de transporte terrestre internacional, empresas públicas de

54 Estudos Feministas, Florianópolis, 23(1): 53-70, janeiro-abril/2015 
${ }^{3} \mathrm{BCN}, 2012$.

${ }^{4}$ CEPAL, 2007, p. 94.

\footnotetext{
${ }^{5}$ INIDE, 2011 a.
}

${ }^{6}$ INIDE, $2011 \mathrm{~b}$. comércio, cooperativas e agências de microcrédito, apicultura, etc. Por sua vez, ampliou-se a cobertura da medição econômica da construção civil, hotéis e restaurantes, serviços de renda de imóveis, etc. ${ }^{3}$ Esse avanço metodológico é importante, dado que se tem uma melhor noção da capacidade produtiva nicaraguense.

Além disso, esse redesenho do Sistema de Contas Nacionais é importante, porque, ao se reduzir a subestimação do PIB, reduzem-se os esforços de política econômica principalmente a fiscal - necessários para cumprir com os programas de estabilização macroeconômica comprometidos com os organismos financeiros internacionais. Esse cumprimento é necessário para o desembolso de empréstimos concessionais para um Estado que não é sujeito de crédito em termos comerciais no mercado internacional.

Levando em conta que $44,4 \%$ do valor adicionado da produção nacional é gerado pelas famílias e $39,0 \%$, pelas empresas, questiona-se por que a análise macroeconômica não incorpora o trabalho doméstico das donas de casa como uma atividade que gera riqueza.

São poucos os países que reconhecem a contribuição econômica do trabalho doméstico, apesar do acordo assinado por 187 Estados na Quarta Conferência Mundial sobre as Mulheres das Nações Unidas, realizada em 1995. Na América Latina, já existem exemplos onde a legislação estabelece o mandato de contabilizar a contribuição econômica do trabalho das donas de casa. Um desses casos é a cidade autônoma de Buenos Aires, Argentina, em que a Lei 1.168 , de 2003, estabeleceu a obrigatoriedade da realização de levantamentos periódicos do aporte econômico do trabalho das donas de casa na economia municipal. ${ }^{4}$

O propósito deste artigo é caracterizar o perfil socioeconômico das mulheres nicaraguenses não inseridas no mercado de trabalho remunerado e refletir sobre os reflexos da falta de reconhecimento do trabalho reprodutivo na vida econômica do país.

\section{Procedimentos metodológicos}

Realizou-se uma pesquisa exploratório-descritiva e de natureza quantitativa que utilizou o banco de dados da Pesquisa Domiciliar de Medição de Nível de Vida (EMNV, por suas siglas em espanhol). A última EMNV foi realizada em 2009, sendo a base de dados publicada em 201 1, pelo Instituto Nacional de Informação de Desenvolvimento (INIDE, por suas siglas em espanhol). ${ }^{5}$

A base de dados da EMNV 2009 foi composta de 7.520 domicílios, totalizando 30.432 pessoas entrevistadas, o que, segundo $\circ$ INIDE, ${ }^{\circ}$ permite obter estimativas nacionais, 
7 De acordo com INIDE (2011), em 2009, a Nicarágua tinha 5,7 milhões de habitantes.
${ }^{8}$ Os únicos levantamentos que contém uma seção do uso do tempo são as EMNV de 1998 e 2001 abrangendo as áreas urbanas e rurais e as sete macrorregiões da Nicarágua. ${ }^{7}$ Para o presente artigo, utilizou-se o fator de expansão incorporado na base de dados para fazer generalizações sobre as características populacionais.

A amostra estudada pela EMNV 2009 se localiza, em $71,3 \%$ dos casos, na área urbana, sendo $51,3 \%$ dos respondentes, mulheres. Em relação à inserção no mercado de trabaIho remunerado, do total de 2,23 milhões de pessoas ocupadas, 1,43 milhões eram homens (64\%) e 796 mil, mulheres (36\%).

A população estudada foi composta pelas mulheres em condição de chefes ou esposas que estavam desempregadas formalmente e que declararam ter, como atividade principal, os afazeres domésticos.

Na seção econômica da EMNV 2009, o trabalho doméstico é registrado como "afazeres do lar", sendo considerado uma inatividade econômica ou desocupação, igualando-se à condição de estudantes, aposentados, inválidos, etc. Isso reflete uma ótica patriarcal na constituição metodológica das estatísticas oficiais no que se refere ao trabalho exercido principalmente por mulheres.

Nesse sentido, não sendo considerado como uma atividade geradora de renda, a pesquisa não mostra o número de horas dedicadas ao trabalho doméstico, perdendo-se assim um importante fator de correlação para a análise. A pesquisa mais recente das condições de vida das famílias nicaraguenses a incorporar informações sobre o uso do tempo foi a EMNV 2001. ${ }^{8}$ Em relação ao trabalho reprodutivo, as principais conclusões derivadas desse levantamento foram: (1) das atividades que faziam parte do trabalho reprodutivo, o transporte de lenha e o conserto de casas eram predominantemente realizados por homens, enquanto cozinhar, limpar a casa e cuidar dos filhos(as) e doentes, pelas mulheres; (2) a média de tempo dedicada ao trabalho reprodutivo por homens era a metade do gasto pelas mulheres; (3) as mulheres casadas ou com companheiro estável relataram os maiores valores de tempo dedicado ao trabalho reprodutivo, com 7,0, 6,6 e 7,4 horas por dia nas áreas nacional, urbano e rural, respectivamente, ao passo que o tempo gasto pelos homens não diferia por estado civil ou por área de residência, com aproximadamente 3,0 horas diárias; (4) menos de $50 \%$ dos homens empregados se envolviam no trabalho reprodutivo e gastavam, em média, 2,8 horas por dia, enquanto a porcentagem de mulheres empregadas fora do lar e envolvidas no trabalho reprodutivo excedia $80 \%$ e gastava, em média, 4,6 horas por dia; e, (5) nas famílias em que ambos os cônjuges estavam inseridos no trabalho remunerado, as mulheres gastavam uma média de 5,0 horas por dia no trabalho reprodutivo, ao passo que os maridos, 2,6 horas, ou seja, eles

56 Estudos Feministas, Florianópolis, 23(1): 53-70, janeiro-abril/2015 
9 Mercedes AGUILAR e Isolda ESPINOSA, 2003, p. 31-35.

${ }^{10}$ INIDE, $2011 \mathrm{~b}$
11 Helena HIRATA e Danièle KERGOAT, 2008, p. 264.

12 Sayyid Salman RIZAVI $e$ Catherine SOFER, 2008, p. 115 não compartilhavam as atividades reprodutivas atribuídas às mulheres. ${ }^{9}$

Com respeito à renda dos lares com trabalhadoras domésticas, procurou-se estimar a renda familiar mensal para cada residência. A seção econômica da EMNV 2009 apresenta informações do primeiro e segundo trabalhos das pessoas, assim como as remunerações pagas em espécie. A metodologia desenvolvida busca homogeneizar a renda, monetária ou não, com o fim de obter um valor final em córdobas (C\$) que indique renda total disponível para a residência $X i$, onde $i: 1,2,3,4 \ldots n$, em termos de frequência mensal.

O Instituto Nacional de Informação de Desenvolvimento (INIDE) ${ }^{10}$ estabelece que a renda dos lares pode ser obtida por duas grandes fontes: (1) renda proveniente das atividades de trabalho; e (2) renda proveniente de atividades diferentes ao trabalho.

Utilizando a base de dados de "População" da EMNV 2009, obtém-se a renda do lar, levando-se em conta: (1) salário líquido do trabalho primário, uma vez deduzidos INSS e IR; (2) salário líquido do trabalho secundário, uma vez descontados INSS e IR; (3) comissões, horas extras e gorjetas obtidas em média durante o mês anterior à entrevista, para o trabalho primário e secundário; (4) décimo terceiro salário para trabalho primário e secundário; (5) pagamento em espécie: alimentos, habitação, roupa e transporte; e (6) autoconsumo para empregadores, empregados por conta própria e membros de cooperativas, nos trabalhos primários e secundários.

Após a tabulação da renda, esta foi transformada em uma frequência mensal, assumindo-se que ela é recebida de forma periódica, sendo convertida em dólares por meio da taxa de câmbio média do ano 2009, de C\$20,34 x US\$ 1,00.

\section{Revisão de literatura}

As pesquisas sobre o trabalho doméstico começaram no início dos anos 1970, na França, quando o movimento feminista denunciou que "[...] uma enorme massa do trabalho é efetuada gratuitamente pelas mulheres; que esse trabalho é invisível e que é realizado não para elas mesmas, mas para outros, e sempre em nome da natureza do amor e do dever materno [...]". ${ }^{1}$

As comparações sobre o uso do tempo no lar revelam que existe uma repartição desigual das tarefas domésticas entre homens e mulheres, mesmo em países mais desenvolvidos. Em uma amostra de 10 países da União Europeia, Rizari e Sofer ${ }^{12}$ encontraram que as mulheres se encarregam de uma proporção do trabalho doméstico que varia entre $60 \%$ e $67 \%$. 
${ }^{13}$ RIZAVI e SOFER, 2008, p. 115

${ }^{14}$ Laís ABRAMO e Rosalba TODARO, 2008, p. 145

${ }^{15}$ Sarah GAMMAGE e Mónica OROZCO, 2008, p. 18-23.

${ }^{16}$ Mercedes AGUILAR e Isolda ESPINOSA, 2004

17 FIDEG, 1995-1996 apud Sonia AGURTO, 2002, p. 14.

${ }^{18}$ CEPAL, 2010, p. 175.

${ }^{19}$ Karina BATTHYÁNY, 2004, p. 31.
No mesmo artigo, Rizavi e Sofer ${ }^{13}$ estudaram o tempo gasto pelos homens e pelas mulheres no trabalho remunerado na França e nos Estados Unidos, ressaltando que, para os casais com filhos pequenos (de zero a três anos), existe um efeito negativo mais forte sobre a oferta de trabalho para as mães do que para os pais.

Por outro lado, existem argumentos que explicam que a supremacia masculina no mercado de trabalho se deve à diferença nos custos de contratar homens e mulheres. Em um estudo sobre os gastos de se empregar homens e mulheres na Argentina, México, Uruguai, Brasil e Chile, Abramo e Todaro encontraram que existe uma baixa incidência anual de gestações e que o salário-maternidade não é financiado diretamente pelos empregadores. Isso resulta em um dispêndio financeiro reduzido, por parte dos empregadores, com o pagamento da licença-maternidade, o que, segundo as autoras, "[...] enfraquece o argumento de que a licençamaternidade e outras prestações associadas a ela implicam custos adicionais elevados [...]". ${ }^{14}$

Em estudos específicos da região mesoamericana, ${ }^{15}$ também se evidencia uma maior participação das mulheres no trabalho doméstico. No México, estima-se que as mulheres dedicam cerca de cinco vezes mais tempo que os homens ao trabalho doméstico, enquanto na Guatemala, mais de quatro horas diárias a mais que os homens. As autoras calculam que o valor monetário das horas de trabalho doméstico realizado por homens e mulheres equivale a cerca de $20 \%$ do PIB para o México e entre $26 \%$ e $34 \%$ do PIB para a Guatemala.

Em se tratando da Nicarágua, o estudo pioneiro de Aguilar e Espinosa ${ }^{16}$ indica que o trabalho doméstico realizado pelas mulheres em 1998 representava $23 \%$ do PIB nacional. Um estudo da Fundação Internacional para o Desafio Econômico Global (FIDEG) ${ }^{17}$ concluiu que o trabalho doméstico realizado pelas mulheres nos anos 1995-1996 representava entre $22 \%$ e $27 \%$ do PIB nicaraguense.

A falta de reconhecimento da importância econômica das tarefas domésticas representa uma discriminação social contra as mulheres. Tal discriminação parte do pressuposto cultural de que o trabalho doméstico é natural das mulheres e que elas o fazem não como uma atividade econômica, mas como um ato de carinho.

Segundo a Comissão Econômica para América Latina e o Caribe (CEPAL), ${ }^{18}$ tal pressuposto ocasiona duas formas de inequidade: primeiro, o trabalho "natural" não é trabalho; e segundo, o trabalho remunerado da mulher é secundário e, portanto, pode ser mais mal remunerado e mais instável do que o masculino, ou mesmo ser eliminado. Segundo Batthyány, ${ }^{19}$ a própria natureza das tarefas domésticas diferencia o trabalho doméstico do trabalho 
${ }^{20}$ Sara SILVEIRA. APUD: BATTHYÁNY, 2004, p. 11.

${ }^{21}$ Massimo CANEVACCI, 1985, p. 258.

${ }^{22}$ Zuleika CÂMARA PINHEIRO et al., 2012, p. 24.

${ }^{23}$ Pierre BOURDIEU, 2000, p. 139

${ }^{24}$ MASSI, 1992, p. 39

${ }^{25}$ Rose Marie MURARO, 1997, p. 189 remunerado, uma vez que, enquanto este é realizado durante um horário e prazo definidos, aquele se efetiva todos os dias ao longo da vida de uma pessoa.

Em termos econômicos, o trabalho doméstico não pode ser considerado inferior às outras atividades econômicas, posto que "[...] este trabalho é o que produz bens com a maior externalidade social, sendo determinante para $o$ desenvolvimento das futuras gerações e produzindo benefícios generalizados àqueles que não pagam diretamente por eles [...]". ${ }^{20}$

O trabalho doméstico gera riqueza por meio, entre outras, das seguintes atividades: produção e consumo, cuidado do corpo e da vida humana, procriação, cuidados de crianças, doentes ou idosos, além da reprodução cotidiana da força de trabalho.

É importante mencionar que o maior problema não é a falta de remuneração monetária do trabalho doméstico, mas, sim, "[...] a posição que valoriza a institucionalização do 'lar doméstico' como lugar eterno do específico feminino [...]". ${ }^{21}$ Como indicam Pinheiro et al.:

[...] há uma simbologia na qual é 'natural' as mulheres se ocuparem da administração e da organização da unidade doméstica, como se elas nascessem com uma biologia já moldada, adaptada e preparada para as habilidades, aptidões e destrezas necessárias à execução das tarefas domésticas. Dentro dessa lógica, o trabalho das donas de casa, muitas vezes, é incorporado, por elas mesmas, como sendo um trabalho só delas. ${ }^{22}$

Para Bourdieu, essa incorporação tem determinação histórica, porque, para ele, gênero é "[...] uma instituição que tem sido registrada por milênios na objetividade das estruturas sociais e subjetividade das estruturas mentais [...]". ${ }^{23}$

Segundo Massi, com a emergência da produção mercantil e a progressiva industrialização das economias, rompese não somente a unidade entre família e produção, mas também se dá um divórcio entre o privado e o público. Assim, as atividades domésticas (do âmbito privado) foram perdendo seu caráter econômico. Para Massi, "[...] a divisão entre as duas esferas é tão significativa que a própria mulher só considera trabalho quando a atividade é fora do espaço físico da casa". ${ }^{24}$

Muraro ${ }^{25}$ explica que essa concepção se origina no patriarcado primitivo, quando o homem tornou-se egoísta ao competir com outros homens por terra ou poder. Por outro lado, a mulher manteve seu caráter altruísta porque conservou uma estrutura psíquica semelhante às culturas mais arcaicas. Isso adequou as mulheres para o privado, o mundo dos afetos, e as excluiu da esfera pública, onde se premia a competência. 
${ }^{26}$ MASSI, 1992, p. 123.

${ }^{27}$ Juliet MITCHELL. APUD: CANEVACCI, 1985, p. 47. Grifo do autor.

${ }^{28}$ Bila SORJ, 2005, p. 83.

${ }^{29}$ BATTHYÁNY, 2004, p. 31.
Ao reconhecer as famílias como a matéria-prima do tecido social, é preciso dar importância à cotidianidade das donas de casa, uma vez que são essas mulheres que estruturam, organizam e mantêm a dinâmica familiar. Como afirma Massi, é "[...] ela [a mulher] quem faz o elo entre a esfera do privado com o social, ou seja, com a família maior, os amigos, a escola, etc." 26

Como a discriminação que sofrem as mulheres donas de casa é uma construção social da divisão sexual do trabalho na cultura patriarcal, sua solução não pode vir de meras reformas na legislação trabalhista, senão de um avanço na consciência social contra essa construção desigual e falsa. Uma crítica das abordagens reformistas é feita por Mitchell, ao afirmar que: "[...] economicamente, a reinvindicação mais elementar não é o direito ao trabalho nem a igualdade de salário, os dois objetivos reformistas tradicionais, mas sim o direito à igualdade de trabalho". ${ }^{27}$

Nessa mesma linha, pode-se afirmar que, enquanto as condições do mercado de trabalho continuarem precárias para as mulheres, continuará o estigma da associação do feminino com o doméstico. Essa percepção é exposta por Sorj ao assegurar que "[...] se elas trabalham em horários reduzidos, se seus empregos são flexíveis, se suas carreiras são menos atraentes, etc., a percepção da afinidade 'natural' entre o feminino e o espaço doméstico encontra boas justificativas para persistir". ${ }^{28} \mathrm{Em}$ muitos países, a precariedade laboral das mulheres resulta no acúmulo de tarefas domésticas e profissionais, sobretudo nas camadas populares.

Assim, como indica Batthyány, "a estrutura social fomenta a participação masculina na vida pública e desanima as mulheres a deixar o lar ou a perseguir carreiras fora das áreas tradicionais de emprego feminino". ${ }^{29}$ Consequentemente, para desconstruir essa falsa noção, a sociedade tem que habilitar e valorar o lugar dos homens no espaço doméstico e no âmbito dos afetos.

\section{Resultados e discussão}

A seguinte seção apresenta os resultados da análise estatística. Primeiro se detalham as condições familiares e econômicas das donas de casa, e posteriormente se calcula a contribuição do trabalho doméstico para a economia nicaraguense. As conclusões acrescentam tanto recomendações de políticas públicas dirigidas às mulheres em estudo quanto sugestões técnicas dirigidas às instituições encarregadas das estatísticas nacionais. 
${ }^{30}$ Sendo que se encontraram apenas 2.453 homens sob esta classificação.

${ }^{31}$ Tania Maria Galli FONSECA 2000

${ }^{32}$ FONSECA, 2000, p. 46

\subsection{Perfil das mulheres trabalhadoras domésticas e características do seu trabalho}

Para definir as mulheres que constituíram a população estudada, a amostra desta pesquisa foi composta por 508.672 mulheres chefes ou esposas dedicadas exclusivamente aos afazeres domésticos, constituindo $42 \%$ das famílias nicaraguenses em 2009, totalizando 2,586 milhões de pessoas. Desse total, $21,8 \%$ eram chefes de família. Nas zonas rurais, essa porcentagem é ainda inferior, com apenas $14,2 \%$ das famílias rurais se declarando chefes da família.

Os dados também mostraram que a quase totalidade $(99,5 \%)$ das pessoas que responderam que tinham como atividade cotidiana principal "afazeres do lar" eram mulheres, ${ }^{30}$ o que indica a naturalização do trabalho familiar como uma atividade do categórico feminino.

Observando a distribuição de homens e mulheres que se declararam responsáveis pelos afazeres domésticos por área de residência, constataram-se mais homens na área urbana e mais mulheres na área rural $(99 \%$ e $54 \%$ do total, respectivamente). A hipótese que poderia explicar essa distribuição cruzada é que, nas áreas rurais, predomina uma cultura mais conservadora, enquanto nas áreas urbanas, os padrões culturais e laborais são mais flexíveis, permitindo que mais homens se dediquem às atividades do lar.

Quando foi questionado às donas de casa por que não procuravam trabalho, a maioria $(90,2 \%)$ respondeu que era por conta de afazeres do lar (Tabela 1). Esse é outro reflexo da naturalização do modelo relacional vigente, com espaços segregados para homens e mulheres, em termos de possibilidades de ações e decisão. As próprias mulheres no seu cotidiano "naturalizam" o papel a elas atribuído na divisão sexual do trabalho, colaborando para a invisibilidade do trabalho desenvolvido.

De acordo com Fonseca, ${ }^{31}$ as tarefas domésticas e o cuidado dos/as filhas/os, exclusivo para as mulheres, são assim caracterizados como trabalho (re)produtivo ocultado, negligenciado e desvalorizado pelo contexto social. As funções desempenhadas pelas mulheres no sustento da casa são invisíveis e desqualificadas, devido à crença de que o homem é o legítimo provedor da família, "[...] o que confere uma posição de trabalhadora complementar à mulher, embora os fatos da realidade revelem que as mulheres trabalhadoras muitas vezes são as reais provedoras do sustento familiar". ${ }^{32}$

A segunda razão de elas não procurarem outro emprego foi não ter ninguém para cuidar de seus filhos novos. Ela representou $5,3 \%$ das respostas e sugeriu que uma importante demanda de cuidado infantil não está sendo oferecida 
por creches privadas ou públicas. Com essa informação e com o cálculo da contribuição monetária do trabalho das donas de casa, apresentado no item 5.2, estimou-se que a demanda total por creches ascendia a um mínimo de 34 milhões de dólares, em 2009.

É interessante notar que, como terceira causa da falta de inserção no mercado de trabalho, está a doença crônica/ incapacidade e, em seguida, a gravidez, representando o exemplo clássico de discriminação laboral por determinação biológica.

Dentro dos limites da pesquisa, é importante sublinhar que, ao analisar unicamente o perfil das mulheres desempregadas responsáveis pelas tarefas domésticas, não é considerado o trabalho doméstico daquelas inseridas no mercado de trabalho remunerado e que realizam a dupla jornada. Não se consideram, também, os afazeres domésticos de todas as mães, tias, avôs, irmãs, etc. que tradicionalmente auxiliam as donas de casa. Porém, é impossível identificar essa condição com os dados da EMNV 2009, deixando a iniciativa para estudos posteriores.

Em termos do perfil sociodemográfico das mulheres não inseridas no mercado de trabalho, constatou-se que a maioria constituía uma população adulta, com idade média de 42 anos $( \pm 15,4)$, com mínimo de 14 e máximo de 97 anos, tendo $25 \%$ das mais jovens 30 anos ou menos e $25 \%$ das mais velhas, 54 anos ou mais.

A maioria das donas de casas afirmou estar casada ou com companheiro estável $(84,0 \%)$ no momento da entrevista, seguida por separadas $(8,8 \%)$ e viúvas $(6,3 \%)$. O número médio de membros por domicílio foi de 5,1 , aproximadamente um membro a menos que a média nacional, de 5,9 membros por domicílio. Por outro lado, o número médio de filhos de 14 anos ou menos (proxy de filhos dependentes) foi de $2,8( \pm 1,4)$, para um total de 644.925 filhos(as), com uma distribuição homogênea por sexo de $52 \%$ de filhos homens.

Com uma média de 4,4 anos de educação formal tanto para as chefes como para as esposas ou companheiras, as mulheres donas de casa possuíam níveis educacionais inferiores aos de suas contrapartes chefes e esposos, com médias de 4,8 e 5,7 respectivamente. No entanto, essa superioridade dos homens não persiste nas faixas com maiores níveis de estudo, uma vez que, a partir dos $25 \%$ das pessoas mais escolarizadas, a escolaridade média é similar entre homens e mulheres.

Ao mesmo tempo, é preocupante a diferença educacional entre áreas de residência, já que as donas de casa exibiram uma escolaridade média de 6,3 anos na área urbana e 2,8 anos na zona rural. Para os homens chefes ou esposos dessas famílias, essa média foi de 7,3 e 3,1 anos, respectivamente. 
${ }^{33}$ Segundo o INIDE (2011), uma pessoa vive em situação de pobreza extrema, se seu consumo per capita anual é inferior a US\$ 334,79 dólares estadunidenses.

${ }^{34}$ James FOSTER, Joel GREER e Erik THORBECKE, 1984.

\footnotetext{
${ }^{35}$ INIDE, $2011 \mathrm{~b}$
}

Um dos principais desafios da política pública na Nicarágua é investir em educação pública, para melhorar os níveis de escolaridade da população. De acordo com a EMNV, em 2009 as pessoas tinham uma média de seis anos de escolaridade. Além disso, a diferença entre áreas de residência é significativa, uma vez que os nicaraguenses que vivem em áreas rurais têm níveis de escolaridade consideravelmente mais baixos que os que vivem em áreas urbanas: quatro anos versus sete, respectivamente.

Com referência à condição socioeconômica, tem-se que $43,3 \%$ das donas de casa viviam em situação de pobreza. Desse total, 13,6\% encontravam-se na pobreza extrema, ${ }^{33}$ enquanto $29,6 \%$ eram consideradas pobres. Esses níveis são similares aos níveis nacionais equivalentes a $42,5 \%$ de pobreza geral e $14,6 \%$ de pobreza extrema, para 2009 . Os dados também ilustram o viés rural da pobreza na Nicarágua, pois a porcentagem média de donas de casa não pobres em áreas urbanas era de $75,6 \%$, enquanto em áreas rurais, $40,5 \%$. Um indicador de pobreza mais intuitivo é o coeficiente do hiato, ou profundidade da pobreza, que mede o déficit relativo de consumo dos pobres em relação ao valor da linha de pobreza - a renda necessária para a unidade pobre, família ou pessoa, deixar de ser pobre ou indigente. ${ }^{34} \mathrm{O}$ INIDE estimou o valor da linha de pobreza geral num nível de consumo de C\$11.725,09 (equivalente a US\$ 568,65 ) por pessoa por ano, ou US\$ 48,04 por pessoa, por mês. Para a pobreza extrema, fixou-se uma linha com valor de US\$ 334,79 anuais por pessoa, equivalente a US\$ 27,90 por pessoa por mês. ${ }^{35}$

O hiato da pobreza para as donas de casa revela que, em 2009 , elas requeriam uma renda adicional de $14,0 \%$ e 3,3\% para se situar acima das linhas da pobreza e da pobreza extrema respectivamente; levemente inferiores às médias nacionais do hiato da pobreza e pobreza extrema.

É interessante observar que há uma maior presença de pessoas pobres nas famílias chefiadas por homens, tanto na pobreza geral quanto na extrema. O percentual de membros pobres nas famílias de chefia masculina foi de $52,0 \%$, sendo $33,0 \%$ pobres e 19,0\% pobres extremos. Em contrapartida, nas famílias chefiadas por donas de casa, $49 \%$ dos membros eram pobres, com $32 \%$ de pobres e $17,8 \%$ de pobres extremos. Contudo, na zona rural, essa relação se inverte, visto que a porcentagem de pobres é de 78,8\% em famílias chefiadas por donas de casa e de $65,7 \%$ nas chefiadas por homens.

De acordo com os cálculos do hiato de pobreza e indigência, as pessoas em domicílios chefiados por mulheres donas de casa eram menos pobres que os chefiados pelos esposos/companheiros dessas mulheres. Enquanto em 2009 as famílias chefiadas por homens requeriam uma renda adicional de $18,4 \%$ e 5,4\% para a erradicação da pobreza e 
${ }^{36}$ INIDE, 2011 a

37 Jean-Marc BURNIAUX et al., 1998, p. 82; Michael F. FÖRSTER, 1994, p. 11; OECD, 2011; Rio Group, 2006; Joseph E. STIGLITZ, Amartya SEN e Jean-Paul FITOUSSI, 2009, p. 116.

38 Para uma comparação empírica de várias escalas de equivalência, ver Aldi HAGENAARS et al. (1994).
39 Utilizaram-se o teste U, de MannWhitney, e o teste não paramétrico de medianas para realizar o contraste estatístico, dada a ausência de normalidade na variável dependente e a ampla diferença no tamanho de amostras dos dois grupos de famílias. da extrema pobreza respectivamente, o déficit relacionado às famílias chefiadas pelas donas de casas foi de 16,5\% e $3,7 \%$. Novamente, para a pobreza nas áreas rurais, o hiato foi maior em domicílios chefiados por mulheres: $29,5 \%$ contra $24,7 \%$ para as residentes nas áreas urbanas.

Na sociedade nicaraguense, persiste o problema da desigualdade na distribuição da renda, uma vez que, segundo os dados da $\mathrm{EMNV}^{36}$ os $50 \%$ dos nicaraguenses mais ricos apreenderam $79,8 \%$ da renda total. Para compreender como essa dinâmica afeta o bem-estar das famílias com mulheres donas de casa, continuaremos a examinar a distribuição de renda para essas famílias.

Para analisar os níveis de renda familiar, foram utilizadas escalas de equivalência para fazer ajustes nos rendimentos mensais das famílias, de uma forma que se possibilite a análise do bem-estar relativo das famílias de diferentes tamanhos e composições. Mais especificamente, utilizou-se a escala modificada da Organização para a Cooperação e Desenvolvimento Económico (OECD modified scale), recomendada e utilizada pela OECD e pela Comissão Europeia para analisar, no micronível, os padrões de vida e a pobreza entre arranjos familiares heterogêneos. ${ }^{37,} 38$

A lógica da escala modificada da OECD é incorporar o pressuposto da existência de economias de escala no consumo familiar, uma vez que qualquer membro adicional do agregado necessita de um aumento menos proporcional da renda familiar, a fim de manter um determinado nível de bem-estar.

A ponderação se realiza dividindo a renda do agregado familiar entre a escala de equivalência familiar, que assinala o valor de um ao primeiro adulto na família; 0,5 para o segundo e para cada pessoa subsequente com idade igual ou superior a 14 anos; e 0,3 para cada criança com idade inferior a 14 anos. Essa escala sugere, por exemplo, que, em uma família composta por um casal com um filho de três anos, o chefe iria contribuir com um, o cônjuge com 0,5 e a criança de três anos com 0,3 , dando uma escala total de equivalência de 1,8. Em outras palavras, essa família precisaria de uma renda $20 \%$ maior do que um casal sem filhos para atingir o mesmo padrão de vida.

Assim, nas famílias das donas de casa, encontrou-se uma renda mensal equivalente de US\$ 105 mensais, com mediana de US\$ 76 e sem diferença estatística ${ }^{39}$ - tanto na média quanto na mediana - para o sexo dos chefes.

A Tabela 2 apresenta a distribuição da renda familiar equivalente segundo os quintis da renda.

Como ilustram os dados acima, as famílias estavam, majoritariamente, concentradas nas camadas de menor renda; $56,1 \%$ das famílias estudadas concentram $40 \%$ da 
população mais pobre. Contudo, nessas famílias existia uma menor dispersão da renda, uma vez que a média e a mediana apresentam valores similares nos primeiros quatro quintis. Essa menor assimetria na distribuição da renda familiar não existe no último quintil, que representa os $20 \%$ das famílias mais ricas, apresentando um diferencial de US\$ 72 entre média e mediana. Nessa última faixa populacional, observa-se, por exemplo, que os $10 \%$ das famílias com maior renda recebiam 7,81 vezes mais renda que os $10 \%$ das mais pobres.

Em relação à distribuição da renda dos lares com donas de casa, verificou-se um coeficiente de Gini de 0,44, levemente inferior ao referente à renda do total de lares, que, segundo o INIDE ${ }^{40}$, era de 0,46, na EMNV 2009. Por outro lado, as estimações do Gini segundo o sexo dos chefes sugerem uma melhor distribuição da renda entre as famílias chefiadas por mulheres, com um Gini de 0,38 para as famílias chefiadas por donas de casa e de 0,45 para as famílias chefiadas pelos esposos/companheiros dessas mulheres. Essa desigualdade pode-se visualizar na Figura 3, que apresenta a curva de Lorenz da renda familiar segundo sexo do chefe.

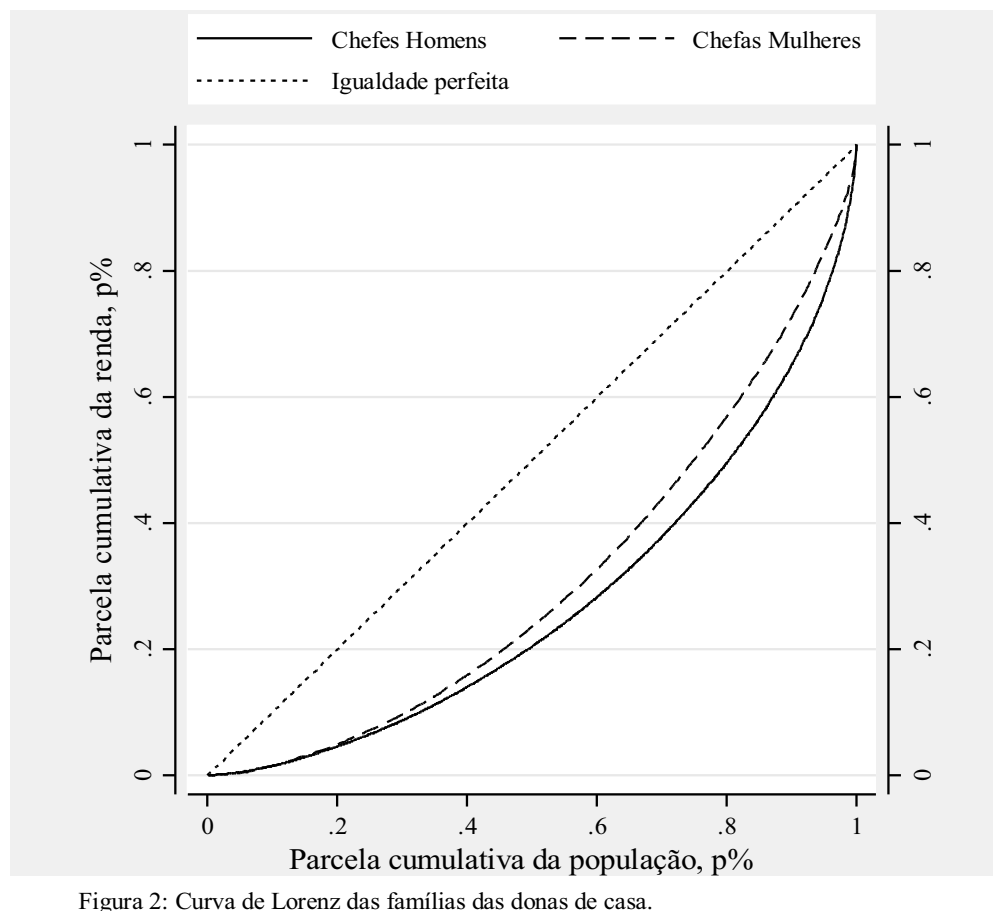

Fonte: com base em dados da EMNV-2009. 
${ }^{41}$ José Ramón LAGUNA e Emilio PORTA, 2013, p. 15.

${ }^{42}$ CEPAL, 2007, p. 94.

${ }^{43}$ GAMMAGE e OROZCO, 2008, p. 16.

${ }^{44}$ Leva-se em consideração o $13^{\circ}$ mês estabelecido na legislação trabalhista.
A maior desigualdade na distribuição da renda presente nas famílias com chefia masculina se explica parcialmente pelos maiores níveis de renda dos homens chefes - principalmente dos mais instruídos -, correspondendo à diferença salarial de gêneros derivada dos retornos mais baixos para a educação feminina na Nicarágua. ${ }^{41}$

\subsection{Contrlbulção monetária do trabalho doméstico}

Para calcular a contribuição monetária das mulheres donas de casa na produção nacional da Nicarágua, foram estudadas 508.672 mulheres que se adequavam a este critério no ano de 2009.

Apesar de compreender que as tarefas domésticas contêm externalidades inestimáveis para o funcionamento da sociedade, em primeira instância foi feito uso do salário mínimo de uma empregada doméstica para o cálculo da remuneração do fator trabalho dessas mulheres, considerando que essa seria a remuneração mínima que essas famílias pagariam a outra pessoa, caso as donas de casa se inserissem no mercado de trabalho remunerado.

Esse cálculo apresenta dificuldades metodológicas que vão além da possiblidade de estudar o trabalho reprodutivo por meio dos levantamentos do uso do tempo, uma vez que não existem atividades comparáveis, no mercado, para o trabalho doméstico, tendo o produto dessas tarefas, muitas vezes, um caráter intangível. ${ }^{42}$ Nesse sentido, a estimativa apresentada pode ser classificada como um cálculo do custo de substituição dos serviços reprodutivos no lar. ${ }^{43}$

Em 2009, a comissão tripartite do salário mínimo estabeleceu um salário de US\$ 107 mensais correspondente às atividades de serviços sociais e pessoais e de empregadas domésticas. Assim, com esse salário mensal recebido por $13^{44}$ meses, a massa salarial total dessas $\mathbf{5 0 8}$ mil trabalhadoras somaria 652 milhões de dólares, equivalente a $8,0 \%$ do PIB nominal total para 2009.

Novamente, ao levar em conta a natureza permanente dos cuidados do lar, tem-se que reconhecer a intensidade ainda que não a qualidade - do trabalho das donas de casa. É nesse sentido que é mais condizente estimar a contribuição monetária dos afazeres domésticos em relação ao salário médio nacional em vez do mínimo das empregadas domésticas, já que este último subvaloriza a produtividade do trabalho reprodutivo.

Por conseguinte, ao alterar o critério salarial, os resultados da contribuição variam drasticamente. Por exemplo, se a renda salarial média da EMNV 2009 é utilizada, a contribuição ascende a $15,8 \%$ do PIB ( $11,6 \%$ ao utilizar a mediana

66 Estudos Feministas, Florianópolis, 23(1): 53-70, janeiro-abril/2015 
${ }^{45}$ Tais serviços seriam, por exemplo, de absorção gratuita de contaminantes, abastecimento de água, energia, diversidade biológica, riqueza genética, etc. da renda salarial). Ao optar pelo salário médio nacional usado pelo BCN, a contribuição seria equivalente a $22,1 \%$ do PIB.

Segundo essas estimativas, com uma contribuição econômica que oscila entre $8,0 \%$ e $22,1 \%$ do PIB, as atividades reprodutivas das donas de casa têm um peso econômico maior ao de várias indústrias incluídas no cálculo atual do PIB. Por serem incluídos no PIB nicaraguense, os afazeres domésticos adicionariam mais valor à oferta produtiva que as atividades de intermediação financeira, construção, exploração mineira, transporte e comunicações, entre outras. De tal modo, assim como o paradigma ortodoxo de crescimento econômico não reconhece os serviços ambientais prestados pela natureza, ${ }^{45}$ as instituições patriarcais encarregadas da medição desse crescimento ainda não reconhecem o subsídio tácito de reprodução social imposta às mulheres.

\section{Conclusões e Recomendações}

Em função dos estereótipos de gênero, o trabalho doméstico é naturalizado como feminino e restringe o desempenho da mulher na vida pública e no mundo do trabalho, o que indica a continuidade dos modelos familiares tradicionais e uma sobrecarga para as mulheres trabalhadoras na Nicarágua.

Considerando que a carga de trabalho doméstico limita o tempo das mulheres para desenvolver atividades geradoras de renda no mercado de trabalho, afetando negativamente a sua empregabilidade, pode-se dizer que a distribuição desigual do trabalho doméstico é um fator de reprodução da pobreza e da desigualdade. Isso deve ser motivo de preocupação para os formuladores de políticas em uma sociedade como a da Nicarágua, com uma concentração de renda nos quintis superiores e com elevados níveis de pobreza, que persistem há décadas.

Uma recomendação específica que resulta da pesquisa é desenvolver esforços no orçamento operativo do INIDE para continuar com a incorporação do módulo de pesquisas do uso do tempo nos levantamentos das pesquisas de domicílios.

Por sua vez, já que a presença de filhos pequenos é um dos fatores relacionados à esfera reprodutiva que mais dificulta a inserção feminina no mercado de trabalho, as políticas públicas deveriam dirigir esforços para prover mais creches, de forma a equilibrar as relações trabalho e família.

Existe, também, a necessidade de conscientizar as mulheres sobre seu poder de moldar o cotidiano familiar e definir os vínculos do lar com os demais atores envolvidos, mais especificamente, com relação a seu poder de negociação com o parceiro. Por conseguinte, conclui-se que a estratégia para a verdadeira emancipação das mulheres donas 
de casa passa por uma (re)significação do papel da paternidade, o que levaria, em última instância, a uma divisão mais justa do trabalho doméstico.

\section{Referências}

ABRAMO, Laís; TODARO, Rosalba. "Custos do trabalho de homens e mulheres na América Latina". In: BRUSCHINI, Cristina et al. (Org.). Mercado de trabalho e gênero: comparações internacionais. Rio de Janeiro: FGV, 2008. p. 141-158.

AGUILAR, Mercedes; ESPINOSA, Isolda. El uso del tiempo de los y las nicaragüenses. Managua: Instituto Nacional de Estadística y Censos (INEC), 2004. ___ Uso del tiempo de los y las nicaraguenses. Managua: INIDE, 2003.

AGURTO, Sonia. "Valoración del trabajo de la mujer en las cuentas nacionales: la experiencia de Nicaragua". In: I CONFERENCIA CENTROAMERICANA YDEL CARIBE. Reducción de la Pobreza, Gobernabilidad, Democracia y Equidad de Género, 2002, Managua. Anais... Managua, 2002.

BANCO CENTRAL DE NICARAGUA. Nota metodológica del Sistema de Cuentas Nacionales de Nicaragua: referencia 2006. Managua: BCN, 2012.

BATTHYÁNY, Karina. Cuidado infantil y trabajo: ¿un desafío exclusivamente femenino?; una mirada desde el género y la ciudadanía social. Montevideo: CINTERFOR, 2004. (Trazos de la formación, 20).

BOURDIEU, Pierre. La dominación masculina. Barcelona: Anagrama, 2000.

BURNIAUX, J.-M. et al. "Income distribution and poverty in selected OECD countries". Economics Department Working Papers, Paris, n. 189, p. 1-175, 1998. Disponível em: <http:/ /www.oecd.org/tax/public-finance/1 864447.pdf>. Acesso em: 10 déc. 2014.

CÂMARA PINHEIRO, Zuleika et al. "Ser dono de casa é uma questão de gênero?" Revista Sociais e Humanas, Cascavel, v. 25, n. 1, p. 23-47, 2012.

CANEVACCI, Massimo. Dialética da família. São Paulo: Brasiliense, 1985.

CEPAL. "Género, trabajo remunerado y no remunerado". In:__. Panorama social de América Latina. Santiago de Chile: Naciones Unidas, 2010. Cap. IV.

. El aporte de la mujer a la igualdad en América Latina. Santiago de Chile: Naciones Unidas, 2007.

CUBERES, David; TEIGNIER, Marc. "Gender gaps in the labor market and aggregate productivity". Sheffield Economic Research Paper, Sheffield, n. 2.012.017, p. 1-31, Jun. 2012.

FONSECA, T. M. G. Gênero, subjetividade e trabalho. Petrópolis: Vozes, 2000. 
FÖRSTER, M. F. "Measurement of low incomes and poverty in a perspective of international comparisons". Labour Market and Social Policy Occasional Paper, Paris, n. 14, p. 1-50, 1994. Disponível em: <http://www.oecd.org/social/soc/ 1895548.pdf >. Acesso em: 8 Dec. 2014.

FOSTER, J. E.; GREER, J.; THORBECKE, E. "A class of decomposable poverty measures". Econometrica, v. 52, p. 761-766, 1984.

GAMMAGE, Sarah; OROZCO, Mónica. El trabajo productivo no remunerado dentro del hogar: Guatemala y México. México, D.F: Naciones Unidas, 2008.

HAGENAARS, A. et al. Poverty statistics in the late 1980s: research based on micro-data. Luxembourg: Office for Official Publications of the European Communities, 1994. p. 415.

HECKMAN, James. J.; LOCHNER, Lance. J.; TODD, Petra E. "Fifty years of mincer earnings regressions". NBER Working Paper, Cambridge, n. 9.732, p. 1-73, 2003.

HIRATA, Helena; KERGOAT, Danièle. Divisão sexual do trabalho profissional e doméstico: Brasil, França, Japão. In: BRUSCHINI, Cristina et al. (Org.). Mercado de trabalho e gênero: comparações internacionais. Rio de Janeiro: FGV, 2008. p. 263-278.

INSTITUTO NACIONAL DE INFORMACIÓN DE DESARROLLO (INIDE). Encuesta Nacional de Hogares para la Medición del Nivel de Vida 2009. Managua. Gobierno de Nicaragua, 2011 a. Disponível em: <http://inide.gob.ni/>

. Encuesta de hogares sobre medición del nivel de vida 2009: principales resultados. Managua: INIDE, $2011 \mathrm{lb}$.

LAGUNA, José R.; PORTA, Emilio. Análisis de la rentabilidad de la educación en nicaragua: documento de trabajo. Managua: FUNIDES, 2013.

LOPEZ, Edgardo. Confidence interval estimantion in quantile regression: a small sample study. Colchester: University of Essex, 2004.

MASSI, Marina. Vida de mulheres cotidiano e imaginário. Rio de Janeiro: Imago, 1992.

MURARO, Rose Marie. A mulher no terceiro milênio. Rio de Janeiro: Rosa dos tempos, 1997.

OECD. "Income and wealth". In:__. . How's life?: measuring well-being. Paris: OECD Publishing, 2011 . p. 284.

RIO GROUP. Compendium of best practices in poverty measurement. Rio de Janeiro: [s.n.], 2006. Disponível em: <http:// www.ibge.gov.br/poverty/pdf/rio_group_compendium.pdf>. Acesso em: 23 Aug. 2014.

RIZAVI, Sayyid Salman; SOFER, Catherine. "Trabalho doméstico e organização do tempo dos casais: uma comparação internacional". In: BRUSCHINI, Cristina et al. (Org.). Mercado de trabalho e gênero: comparações internacionais. Rio de Janeiro: FGV, 2008. p. 107-124. 
SORJ, Bila. "Percepções sobre esferas separadas de gênero". In: ARAUJO, Clara; SCALON, Maria (Org.). Gênero, família e trabalho no Brasil. Rio de Janeiro: Editora FGV, 2005. p. 7988.

STIGLITZ, J. E.; SEN, A.; FITOUSSI, J.-P. Report by the Commission on the Measurement of Economic Performance and Social Progress Sustainable Development. 2009. Disponível em: $<$ http://www.ssrn.com/abstract=1714428 >. Acesso em: 9 Dec. 2014

[Recebido em 7 de outubro 2013 reapresentado em 20 de outubro de 2014 e aceito para publicação em 3 de novembro de 2014]

\section{Nicaraguan Housewives' Socioeconomic Profile}

Abstract: The purpose of this article is to characterize the socioeconomic profile of Nicaraguan housewives and bethink their monetary contribution to national production. The statistics showed that housework, generally invisible and not valued, is women's responsibility. It was estimated that in monetary terms the wage bill of unpaid housework in Nicaragua would range between $8.0 \%$ and $22.1 \%$ of GDP. We conclude that, in spite of its relevance to national production, the place women occupy in society is determined by its role in the family, according to the gender stereotypes.

Key Words: Domestic Work; Gender; National Accounts; Public Policy. 